\title{
Erratum to "Autonomous Changes in the Concentration of Water Vapor Drive Climate Change" [Atmospheric and Climate Sciences 10 (2020) 443-508]
}

\author{
William Van Brunt \\ JFA, LLC, Wayzata, MN, USA \\ Email: WaterVapor@JUstForumAccess.com
}

How to cite this paper: Van Brunt, W. (2021) Erratum to "Autonomous Changes in the Concentration of Water Vapor Drive Climate Change" [Atmospheric and Climate Sciences 10 (2020) 443-508]. Atmospheric and Climate Sciences, 11, 535-546. https://doi.org/10.4236/acs.2021.113032

Received: March 30, 2021

Accepted: June 28, 2021

Published: July 1, 2021

\section{Copyright $\odot 2021$ by author(s) and} Scientific Research Publishing Inc. This work is licensed under the Creative Commons Attribution International License (CC BY 4.0).

http://creativecommons.org/licenses/by/4.0/

(c) (i) Open Access

The original online version of this Article (Van Brunt, W., Autonomous Changes in the Concentration of Water Vapor Drive Climate Change, Atmospheric and Climate Sciences 2020, 10, 443-508,

DOI: 10.4236/acs.2020.104025) was published with certain minor errors and omissions. The author wished to correct the errors to:

\section{Abstract}

A. Changes in average global temperature are not driven by changes in the concentration of carbon dioxide;

B. Instead, autonomous changes in the concentration of water vapor, $\triangle \mathrm{TPW}$, drive changes in water vapor heating, thus, changes in the average global temperature, $\Delta T_{\text {Avg }}$, in deg. Celsius are calculated in accordance with this principle,

$$
\Delta T_{\text {Avg }}=0.4 \Delta \mathrm{TPW}
$$

measured in $\mathrm{kg} \cdot \mathrm{m}^{-2}$, the average accuracy of which is $\pm 0.14 \%$, when compared to the variable annual, 1880 - 2019, average global temperature record;

\section{Introduction}

As shown below, the changes in the concentration of water vapor, $\triangle \mathrm{TPW}$, (the difference between the total rate of average global evaporation compared to the
total rate of average global precipitation, over the same time period), drive
changes in water vapor surface heating, $\Delta \mathrm{WV}$, which in turn drive changes in
the concentration of water vapor. This can, continue in an autonomous positive feedback loop. 
Until that is understood, appropriate solutions found and implemented, this is an ever increasing potential threat to humankind. The good news is that this problem, including the reduction of past increases, at least theoretically, lends itself to solutions.

Between 1880 and 2019, the energy of Earth's land surface increased by $0.7 \%$, an average increase of $0.005 \%$ per year, which is greater than the increase in the surface energy of the seas. No appreciable fraction of the radiant energy heating the surface is stored in the land. Therefore, determining the average annual change in average global temperature from a change in average total heating is a straightforward exercise in thermodynamics. Deduct the percentage of total heating that drives evaporation and thermal convection and, given that the average surface radiation, $\operatorname{Rad}_{\mathrm{U}}$, cannot exceed the remaining net heating, $\mathrm{NaH}$, for small changes in net heating, the change in the average surface temperature from temperature $T_{o}$ is,

\section{$\Delta \mathrm{T}=\Delta \mathrm{NaH} /\left(4 \sigma \mathrm{To}^{3}\right) \quad{ }^{\circ} \mathrm{C}$}

Further, many individual models show year to year

1) variances greater than $20 \%$ of the actual year to year temperature increase between 1880 and 2018;

These hindsight comparisons illustrate the failings of these models.

New Principles

Therefore, new Principles to first determine changes in the average concentration of water vapor and then the ehanges in heating and surface temperature these changes drive, are set out. (The derivation of all of these principles is set out in Appendix 1).

Therefore, wholly new Principles of climate physics for calculating changes in the concentration of water vapor and water vapor heating and resulting changes in average global temperature have been developed. (The derivation of all of these principles is set out in Appendix 1.

The results of the application of these principles are set out and prove that:

That Equation (1) is correct can also be seen from Figure 5 showing the average global concentration of water vapor and the computed concentration of water vapor, TPW, calculated in accordance with Equation (1) for the years 1996-2007, set out in Table 1 and shown as green dots, along with their trendline (dashed red line).

- And after comments such as “...rising average temperature increases evaporation rates and atmospheric water vapor concentrations," a wholly unproven and misconceived, common follow on is something to the effect that, since, "Water vapor cannot itself catalyze temperature increases in the short time (estimated at around 10 days) that a discrete water vapor influx would remain before precipitating out. A sustained increase in tropospheric water vapor requires a strong external forcing to provide the initial temperature increase [10]."

Then the resulting increase in temperature would be an annual increase of 


\section{$1.25^{\circ} \mathrm{C}$}

However, with the theoretical effects of $\mathrm{CO}_{2}$ excluded, Equation (4) still overstates the temperature increase in violation of Kirchoff's law and the first law of thermodynamics. 114 out of $139 \%$ or $82 \%$ are higher than actual, some as great as $0.1^{\circ} \mathrm{C}$. (This is likely due to the fact that the effects of changes in cloud cover are not taken into account in Equation (4)) Therefore, Equation (4) is also not advanced as correct.

Why is $\mathrm{CO}_{2}$ Irrelevant?

- Finally note that, "The average frequency of emission for $\mathrm{CO}_{2}$ is 1.6 times lower than that of the other considered gases. Therefore, the energy efficiency of the resulting $\mathrm{CO}_{2}$ emission, proportional to $\omega$, is almost five times lower than that of the other gases. "See [14] (p. 349, Figure 2.)

Figure 11 Correlation of Changes in Average Global Temperature with Changes in Concentration of Water Vapor [1] [2] [3] (Table S2 Appendix 2, Supplementary Materials)

This relationship is:

$$
\Delta T_{\text {Avg }}=0.4 \Delta \mathrm{TPW}-0.05{ }^{\circ} \mathrm{C}
$$

with an $\mathrm{R}^{2}$ of 0.9953 .

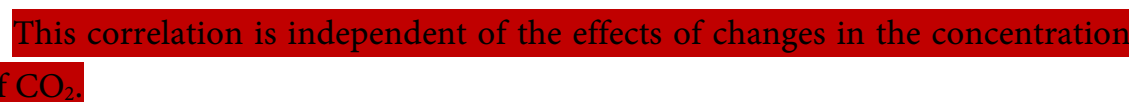

The results of employing this relationsship to determine the average global temperature is shown in Figure 12.

While the theoretical heating by $\mathrm{CO}_{2}$ is also removed in Equation (4), Equation (4), is based upon a theoretical computation of the effects of changes in the concentration of water vapor on surface heating, alone

Equation (5) is based upon a comparison to the actual temperature record,

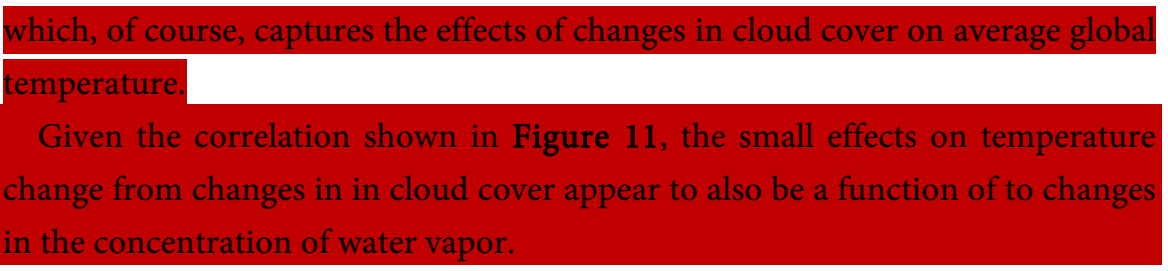

The results from the application of Equation (5) have a correlation coefficient of 09976 , exceeding the average global temperature $68 \%$ of the time, but never by more by more than $0.05^{\circ} \mathrm{C}$, which is itself well within the error band of average global temperature estimates for the period in which this occurred, 19041910 [15].

It is clear therefore, that Equation (5) captures the relationship between changes in the concentration of water vapor and the average global temperature-demonstrating the mechanism driving climate change and validating the physics set out herein.

Thus, Equation (5) is advanced as The Principle of Climate Physics accounting for climate change, which demonstrates that:

a. Changes in the concentration of water vapor, $\triangle \mathrm{TPW}$ not $\mathrm{CO}_{2}$, drive cli- 
mate change;

b. Equation (1) is a valid principle of climate physics;

c. Changes in the concentration of water vapor are sufficient, in and of themselves, to drive all of the changes in heating; and,

d. These changes in water vapor heating and concentration are sufficient to

autonomously drive climate change independent of any other climate factors, in positive feedback loop, as discussed below

In 1977 was the year of the largest single year increase in the concentration of water vapor since $1880,0.74 \mathrm{~kg} \cdot \mathrm{m}^{-2}$ or $4 \%$, which was the start of a major and continuing increase. Before that, the concentration of water vapor increased at a rate of $0.002 \mathrm{~kg} \cdot \mathrm{m}^{-2}$ per year and after 1977 at a rate of $0.06 \mathrm{~kg} \cdot \mathrm{m}^{-2}$ per year, corresponding to an increase of $3.3 \%$ per decade.

From Figure 4, Figure 11, Figure 13, this chart and this expression, it is evident that this increase in average global temperature $\Delta T_{\mathrm{Avg}}$ is ongoing and the result of the change in average global water vapor concentration, $\triangle \mathrm{TPW}$, continuing in an autonomous, roughly 3.5 year, positive feedback cycle.

\section{Discussion}

Since 1976, changes in total heating, $\Delta \mathrm{TH}$, have been the primary driver of evaporation. The resulting increase in water vapor, $\Delta \mathrm{TPW}_{\Delta \mathrm{TH}}$ and water vapor heating, $\Delta \mathrm{WV}_{\Delta \mathrm{TH}}$, which is the most significant change in heating, is responsible, on average, for $\sim 60 \%$ of water vapor heating.

Table 2. Global Average Land, Ocean and Average Steady State Heating Budgets for 1880, 1976 and $2002\left(\mathrm{Wm}^{-2}\right)$.

\begin{tabular}{|c|c|c|c|}
\hline Year & 1880 & 1976 & 2002 \\
\hline Total Heating (TH) & 485 & 486 & 494 \\
\hline Radiant Emittance Rad UL & & & \\
\hline Solar Radiation (Sol) & 161 & 161 & 161 \\
\hline Back-Radiation (BR) & 324 & 325 & 333 \\
\hline Evaporative Power (Evap ${ }_{\text {Avg }}$ ) & 75 & 76 & 80 \\
\hline Thermal Convection (Conv ${ }_{\text {Avg }}$ ) & 18 & 18 & 18 \\
\hline Eff $_{\text {Avg }}$ Steady State & 0.80 & 0.80 & 0.80 \\
\hline \multicolumn{4}{|l|}{ Land Heating Budget } \\
\hline Year & 1880 & 1976 & 2002 \\
\hline Total Heating $(\mathrm{TH})$ & 485 & 486 & 494 \\
\hline Radiant Emittance Rad UL $_{\mathrm{L}}$ & 354 & 356 & 362 \\
\hline Solar Radiation (Sol) & 161 & 161 & 161 \\
\hline Back-Radiation (BR) & 324 & 325 & 333 \\
\hline Evaporative Power $\left(\right.$ Evap $\left._{L}\right)$ & 41 & 41 & 42 \\
\hline Thermal Convection $\left(\right.$ Conv $\left._{\mathrm{L}}\right)$ & 89 & 89 & 91 \\
\hline
\end{tabular}




\section{Continued}

\begin{tabular}{cccc}
\hline $\begin{array}{c}\text { Eff Steady State } \\
\text { Ocean Heating Budget }\end{array}$ & 0.73 & 0.73 & 0.73 \\
Year & 1880 & 1976 & 2002 \\
Total Heating (TH) & 485 & 486 & 494 \\
Radiant Emittance Raduo & 394 & 394 & 397 \\
Solar Radiation (Sol) & 161 & 161 & 161 \\
Back-Radiation (BR) & 324 & 325 & 333 \\
Evaporative Power (Evapo) & 89 & 91 & 96 \\
Thermal Convection (Convo) & 2 & 2 & 2 \\
Effo Steady State & 0.81 & 0.81 & 0.80 \\
\hline
\end{tabular}

Table 3. Breakdown of the Increase in the Heating $\left(\mathrm{Wm}^{-2}\right)$ Required for an Increase in the Global Average Land and Global Average Ocean Temperature between 1880-2002 and 1976-2002.

\begin{tabular}{|c|c|c|}
\hline Global Average & $1976-2002$ & $1880-2002$ \\
\hline Increase in the average global temperature $\left({ }^{\circ} \mathrm{C}\right)$ & 0.7 & 0.8 \\
\hline $\begin{array}{l}\text { Increase in total heating, } \Delta \mathrm{TH} \text { required for this } \\
\text { increase in temperature } \mathrm{Wm}^{-2}\end{array}$ & 7.7 & 9.4 \\
\hline \multicolumn{3}{|l|}{ Increase in radiant emittance $\left(\Delta \operatorname{Rad}_{\text {UAvg }}\right) \mathrm{Wm}^{-2}$} \\
\hline Change in solar radiation $(\Delta \mathrm{Sol}) \mathrm{Wm}^{-2}$ & 0.0 & 0.0 \\
\hline Increase in back radiation $(\Delta \mathrm{BR}) \mathrm{Wm}^{-2}$ & 7.7 & 9.4 \\
\hline \multicolumn{3}{|l|}{ Increase in evaporative power $\left(\Delta\right.$ Evap $\left._{\text {Avg }}\right) \mathrm{Wm}^{-2}$} \\
\hline Change in thermal convective power $\left(\Delta\right.$ Conv $\left._{\text {Avg }}\right) \mathrm{Wm}^{-2}$ & 0.4 & 0.5 \\
\hline Eff $_{\Delta T H T o t A v}$ & 0.73 & 0.77 \\
\hline
\end{tabular}

Since 1976, changes in total heating, $\Delta \mathrm{TH}$, have been the primary driver of evaporation. The resulting increase in water vapor, $\Delta \mathrm{TPW}_{\Delta \mathrm{TH}}$ and water vapor heating, $\Delta \mathrm{WV}_{\Delta \mathrm{TH}}$, which is the most significant change in heating, is responsible, on average, for $\sim 60 \%$ of water vapor heating.

\section{Results}

f) Is validated by the determinations of average global temperatures, going back to 1880 , which, from the application of Equations (1) \& (5) are shown to be a function of changes in the concentration of water vapor,

$$
\text { ii. } \Delta T_{\text {Avg }}=0.4 \Delta \mathrm{TPW}-0.045^{\circ} \mathrm{C}
$$

with a $R^{2}$ of 0.9953 (See Figure 11) and an average accuracy of $\pm 0.14 \%$.

In 1977 there was the largest single year increase in the concentration of water vapor since $1880,0.74 \mathrm{~kg} \cdot \mathrm{m}^{-2}$ or $4 \%$, which was the start of a major and continuing increase. Before that, the concentration of water vapor increased at a rate of $0.002 \mathrm{~kg} \cdot \mathrm{m}^{-2}$ per year and after 1977 at a rate of $0.05 \mathrm{~kg} \cdot \mathrm{m}^{-2}$ per year, which cor- 
responded to an increase of $4 \%$ per decade.

Referring to Equations (3) \& (5) and Figure 4, there can be no doubt that changes in the concentration of water vapor drive changes in water vapor heating and therefore, in average global temperature. The correlation coefficient between changes in water vapor concentration and average global temperature is 0.9953 . Changes in water vapor heating drive changes in evaporation. To the extent that the average evaporative rate exceeds the average rate of precipitation, the concentration of water vapor will increase. There is no drag on the system. This a classic positive feedback loop, which means that, absent some external intervention, as long as this imbalance continues, global warming will increase. See Figure 15.

\section{Conclusion}

\section{In Sum}

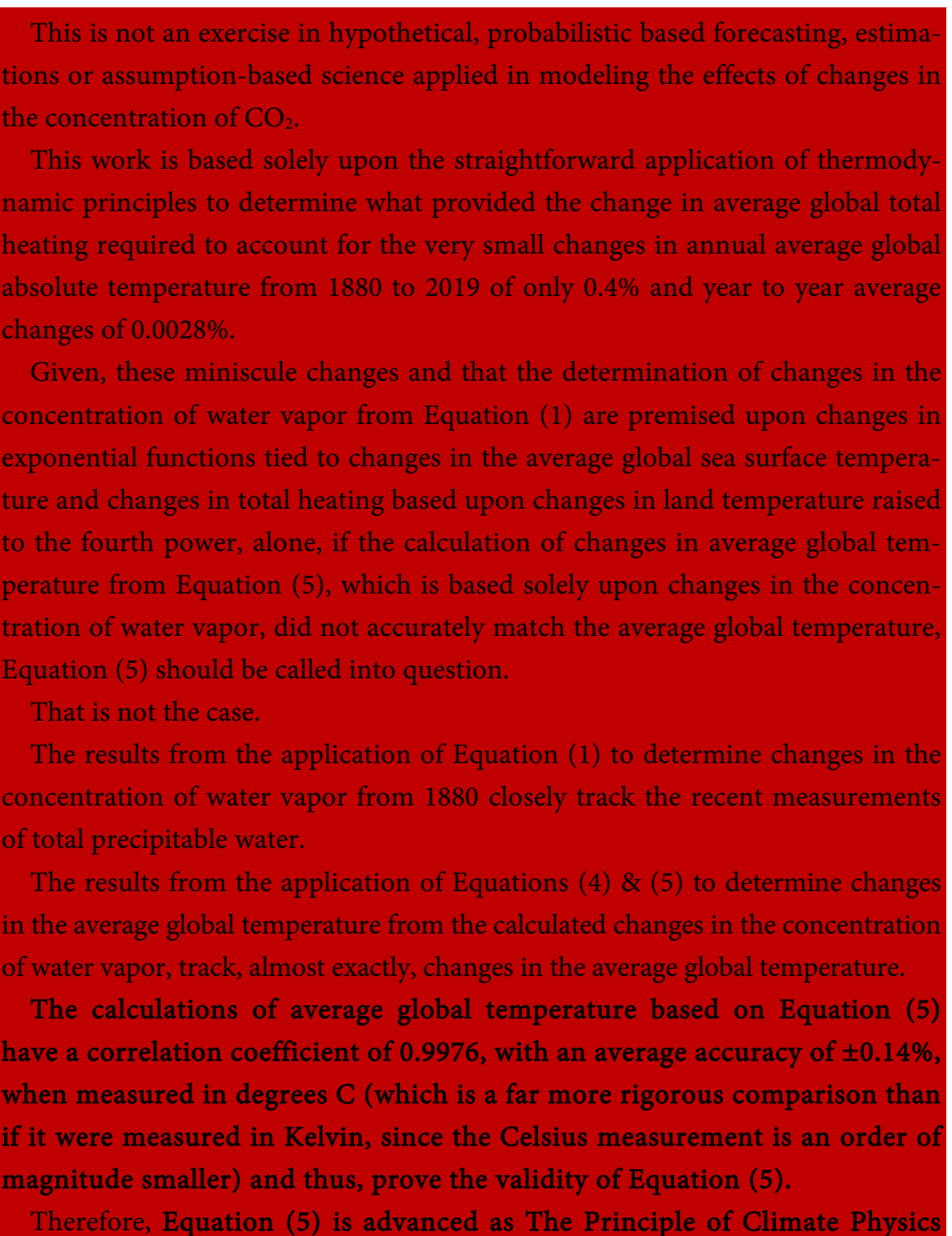




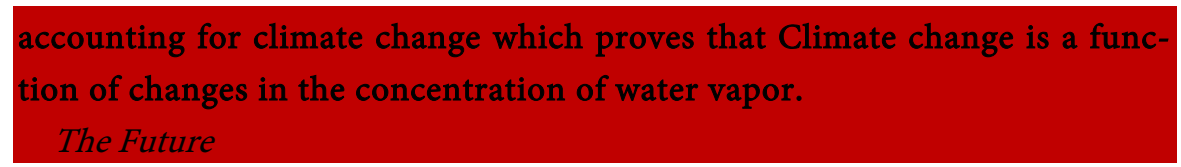

The climate reached a tipping point in 1977 when, compared to 1880 , the concentration of water vapor jumped by $4 \%$, the greatest short-term increase since then. Thereafter, the rate of increase in evaporation on average, continued to exceed the rate of increase in precipitation.

However, if the atmospheric density of $\mathrm{CCN}$ can be increased to the point that average annual precipitation can again equal or exceed average annual evaporation, global warming can not only be halted-it can be reversed. There can, at least in theory, be an immediate resolution.

\section{Conflicts of Interest}

The authors declare no conflicts of interest regarding the publication of this paper.

\section{References}

[1] NOAA National Centers for Environmental Information: Land Data, Climate at a Glance: Global Time Series. Available Online:

https://www.ncdc.noaa.gov/cag/time-series (Last Accessed 3/5/2020).

[2] NOAA National Centers for Environmental Information: Ocean Data, Climate at a Glance: Global Time Series. Available Online:

https://www.ncdc.noaa.gov/cag/time-series (Last Accessed 3/5/2020). 


\section{Appendix 1. Derivation of Formulations and Definition of Terms}

\section{Nomenclature}

Conv heating flux that drives thermal convection, $\mathrm{Wm}^{-2}$

$\Delta T \quad$ change in temperature, ${ }^{\circ} \mathrm{C}$

Eff heating efficiency-the fraction of total heating remaining after the deduction of evaporative and convective losses,

$$
\text { Eff }=1-(\text { Evap }+ \text { Conv }) / T H
$$

Evap heating flux absorbed by evaporation, $\mathrm{Wm}^{-2}$

GHG Greenhouse Gases

IR Infrared Radiation

Since, the efficiency factor for land with respect to changes in total heating, $\mathrm{Eff}_{\Delta \mathrm{THL}}$ from Table 3, is 0.8 , then

$$
\begin{gathered}
\Delta \mathrm{NaH}_{\mathrm{L}}=\mathrm{Eff}_{\Delta \mathrm{THL}} \Delta \mathrm{TH}=0.8 \Delta \mathrm{TH} \\
\Delta T_{\text {STLL }}=\left(6.34 \times 10^{9}+0.8 \Delta \mathrm{TH} / 5.67 \times 10^{-8}\right)^{1 / 4}-281.2
\end{gathered}
$$

Another approach-taking the first derivative, the change for surface radiation, $\Delta \operatorname{Rad}_{\mathrm{UL}}$, as a function of changes in land temperature, is,

From Table 2 \& Table 3

$$
\begin{gathered}
\operatorname{Eff}_{\text {SSL }}=0.73 \\
\operatorname{Eff}_{\Delta \mathrm{THL}}=0.8 \\
\mathrm{NaH}_{\mathrm{LN}}=0.73 \mathrm{TH}_{\mathrm{Lo}}+0.8 \Delta \mathrm{TH} \\
\mathrm{NaH}_{\mathrm{LN}}=\mathrm{NaH}_{\mathrm{Lo}}+\Delta \mathrm{NaH}_{\mathrm{L}} \\
\Delta \mathrm{NaH}_{\mathrm{L}}=\mathrm{NaH}_{\mathrm{LN}}-\mathrm{NaH}_{\mathrm{Lo}}=\mathrm{Eff}_{\mathrm{SSL}} \mathrm{TH}_{\mathrm{Lo}}+\mathrm{Eff}_{\Delta \mathrm{THL}} \Delta \mathrm{TH}-\mathrm{Eff}_{\mathrm{SSL}} \mathrm{TH}_{\mathrm{Lo}} \\
\Delta \mathrm{NaH}_{\mathrm{L}}=\mathrm{Eff}_{\Delta \mathrm{THL}} \Delta \mathrm{TH} \\
\Delta T_{\mathrm{STLL}}=0.198 \Delta \mathrm{NaH}_{\mathrm{L}}=0.198 \mathrm{Eff}_{\Delta \mathrm{THL}} \Delta \mathrm{TH}=0.198 \times 0.8 \Delta \mathrm{TH}
\end{gathered}
$$$$
\Delta T_{\text {STLL }}=0.157 \Delta \mathrm{TH}^{\circ} \mathrm{C}
$$

D.) Change in ocean temperature from changes in total heating, $\left.\Delta T_{\Delta \mathrm{THO}}\right)$.

For Eff $_{\Delta \mathrm{THO}}=0.36$

$$
\begin{gathered}
\Delta \operatorname{Rad}_{\text {U080-19 }}=0.36 \Delta \mathrm{TH} \\
\Delta T_{\text {STLO }}=0.183 \times 0.36 \Delta \mathrm{TH} \\
\Delta T_{\text {STLO }}=0.07 \Delta \mathrm{TH}^{\circ} \mathrm{C}
\end{gathered}
$$

Changes in the Concentration of Water Vapor

The total concentration of water vapor, total precipitable water $\left(\mathrm{TPW}_{\mathrm{Tot}}\right)$, is the sum of the concentration of water vapor from steady state evaporation as a function of sea surface temperature, TPW $\mathrm{SST}_{\text {and }}$ ananges in concentration in response to changes in total heating, $\triangle \mathrm{TPW}_{\triangle \mathrm{TH}}$.

$$
\mathrm{TPW}_{\mathrm{ToT}}=\mathrm{TPW}_{\mathrm{SST}}+\Delta \mathrm{TPW}_{\Delta \mathrm{TH}} \mathrm{kg} \cdot \mathrm{m}^{-2}
$$


Changes in concentration of Water Vapor from changes in steady state Sea Surface Temperature, SST.

The results from Equation (13), for sea surface temperatures for 1880 and 2019, temperatures of 288.67 and $289.37 \mathrm{~K}$, are a $5 \%$ increase in water vapor concentration in 2019 over 1880 .

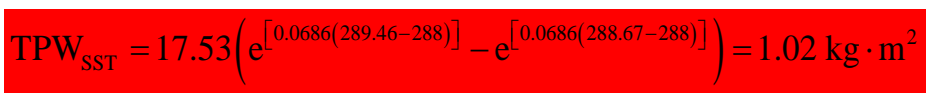

In 1880 , the initial water vapor concentration, $\mathrm{TPW}_{1880}$, calculated in accordance with Equation (12), for SST $=288.67 \mathrm{~K}$, was $18.35 \mathrm{~kg} \cdot \mathrm{m}^{-2}$.

Then, this increase was,

$$
1.02 / 18.35=5 \%
$$

Changes in Water Vapor Concentration Driven by Changes in Total Heating

Assume, the rate of evaporation is proportional to the fraction of heating flux driving evaporation from the seas, Evapo.

\section{$\mathrm{EV} \propto \mathrm{E}_{\text {vap }}$}

Therefore, changes in the concentration of water vapor are proportional to changes in the heating that drives evaporation.

\section{$\therefore \triangle \mathrm{TPW} \propto \Delta \mathrm{E}_{\mathrm{vi}}$}

with changes in water vapor concentration, $\triangle \mathrm{TPW}$, proportional to changes in evaporative power, this means that:

\section{$\Delta \mathrm{TPW} \propto \Gamma \Delta \mathrm{E}_{\mathrm{va}}$}

\section{where $\Gamma$ is a constant.}

In 1880, when the change in average global temperature and therefore, total heating, was minor, ignoring changes in total heating for that year, the initial water vapor concentration, $\mathrm{TPW}_{1880}$, calculated in accordance with Equation (12) for SST $=288.67 \mathrm{~K}$, was $18.35 \mathrm{~kg} \cdot \mathrm{m}^{-2}$. So,

$$
\mathrm{TPW}_{1880}=\Gamma \mathrm{Evap}_{1880}
$$

Since changes in evaporative powe are proportional to changes in total heating, And, for changes in the evaporative power, therefore changes in total heating, $\triangle T H$, the change in water vapor concentration driven by changes in total heating, $\triangle T P W \triangle T H O$ is

$\triangle \mathrm{TPW} \triangle \mathrm{THO}=\mathrm{T} \triangle \mathrm{EvapO}$

From Table 2, the steady state power driving evaporation for the seas in 1880, Evapo, was $89 \mathrm{Wm}^{-2}$ and for land, Evap $\mathrm{L}_{\mathrm{L}}, 42 \mathrm{Wm}^{-2}$. The total evaporative power is the area weighted average of the two,

$$
\begin{gathered}
\text { Evap }_{1880 \mathrm{Tot}}=\% \text { Area Ocean } \times \text { Evap }_{18800}+\% \text { Area Land } \times \text { Evap }_{1880 \mathrm{~L}} \\
\text { Evap }_{1880 \mathrm{Tot}}=71.11 \% \times 89+29.89 \% \times 42=75.3 \mathrm{~W} \cdot \mathrm{m}^{-2}
\end{gathered}
$$

\section{Thus,}

$\Gamma=\mathrm{TPW}_{1880} / \mathrm{Evap}_{1880 \mathrm{Tot}}=18.35 / 75.3=0.24$ 
For the seas, ignoring changes in thermal convection, the change in evaporative power, $\Delta$ Evapo, in response to changes in total heating, $\Delta \mathrm{TH}$, is the fraction of the change in total heating, $\Delta \mathrm{TH}$, that does not drive an increase in temperature, $\left(1-\mathrm{Eff}_{\Delta \mathrm{THO}}\right) \Delta \mathrm{TH}$, then

$$
\Delta \text { Evapo }=\left(1-\mathrm{Eff}_{\Delta \mathrm{THO}}\right) \Delta \mathrm{TH},
$$

Assume, the average concentration of water vapor, TPW, from the seas $\mathrm{TPW}_{\mathrm{O}}$, is similarly proportional to the evaporation from the seas, Evapo. Thus,

$$
\mathrm{TPW}_{\mathrm{O}}=\Gamma \text { Evapo }_{\mathrm{O}}
$$

$$
\Delta \mathrm{TPW}_{\Delta \mathrm{THO}}=\Gamma \Delta \mathrm{Evapo}=\Gamma\left(1-\mathrm{Eff}_{\Delta \mathrm{THO}}\right) \Delta \mathrm{TH},
$$

\section{From Table 3}

$$
\mathrm{Eff}_{\Delta \mathrm{THO}}=0.36
$$

Hence,

\section{$\Delta \mathrm{TPW}_{\Delta \mathrm{THO}}=0.24(1-0.36) \Delta \mathrm{TH}$}

$\Delta \mathrm{TPW}_{\Delta \mathrm{THO}}=0.157 \Delta \mathrm{TH}$

Between 1880 and 2019, this factor alone, $\Delta \mathrm{TPW}_{\Delta \mathrm{THO}}$, accounts for an increas

$\mathrm{n}$ the concentration of water vapor of $2 \mathrm{kgm}^{-2}$ or $100 \%$ more than the changes n sea surface temperature can account for

Then, since

$\Gamma=\Delta \mathrm{TPW} \Delta \mathrm{TH} \mathrm{H} /((1-\mathrm{Eff} \Delta \mathrm{TH} \mathrm{H}) \Delta \mathrm{TH})$,

Therefore,

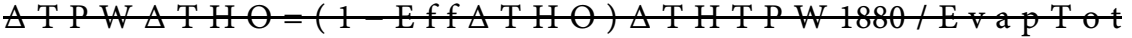
1880

$\triangle \mathrm{TPW} \triangle \mathrm{TH} \mathrm{O}=18.35(1-0.36) \triangle \mathrm{TH} / 75.3$

$\triangle \mathrm{TPW} \triangle \mathrm{THT} \mathrm{Tt}=0.157 \triangle \mathrm{TH}(14)$

Total Change in the Concentration of Water Vapor

Taking into account changes in evaporation from changes in total heating, $\Delta \mathrm{TH}$ and sea surface temperature, $\Delta \mathrm{SST}$, the total change in the concentration of water vapor is therefore,

$$
\Delta \mathrm{TPW}_{\mathrm{Tot}}=\Delta \mathrm{TPW}_{\Delta \mathrm{TH}}+\Delta \mathrm{TPW}_{\mathrm{SS}}
$$

\section{Thus,}

Changes in Water Vapor Heating from Changes in Concentration of Water Vapor

Then to determine the change in water vapor heating, $\Delta \mathrm{WV}_{1880-2002}$, from $\underline{\mathrm{Ta}}$ ble 2 and om Table S1,

$$
\begin{gathered}
\mathrm{WV}_{\mathrm{Tot} 1880}=\mathrm{BR}_{1880}-\mathrm{TH}_{\mathrm{CO} 21880}=322.73-30.35=292.38 \mathrm{~W} \cdot \mathrm{m}^{-2} \\
\mathrm{WV}_{2002}=\mathrm{BR}_{2002}-\mathrm{TH}_{\mathrm{CO} 22002}=\mathrm{BR}_{2002}-\left(\mathrm{TH}_{\mathrm{CO} 21880}+\Delta \mathrm{TH}_{\mathrm{CO} 21880-2002}\right)
\end{gathered}
$$

And from Equation (14)

$$
\Delta \mathrm{TPW}_{\Delta \mathrm{TH}}=0.157 \Delta \mathrm{TH}
$$

From 
Thus,

$$
\begin{gathered}
\Delta \mathrm{TPW}_{\text {SST1880-2002 }}=17.53\left(\mathrm{e}^{0.081}-\mathrm{e}^{0.046}\right) \\
\Delta \mathrm{TPW}_{\text {SST1880-2002 }}=17.53\left(\mathrm{e}^{0.081}-\mathrm{e}^{0.046}\right)=0.654
\end{gathered}
$$$$
\Delta \mathrm{TPW}_{\text {Tot1880-2002 }}=\Delta \mathrm{TPW}_{\Delta \mathrm{THW} 1880-2002}+\Delta \mathrm{TPW}_{\mathrm{SSTW} 1880-2002}
$$$$
\Delta \mathrm{TPW}_{\text {Tot1880-2002 }}=1.48+0.654=2.134
$$

Thus,

$$
\mathrm{WV}=73.3 \ln (\mathrm{TPW})+79.1
$$

Changes in Water Vapor Heating from Changes in Total Heating

Changes in Water Vapor Heating from Steady State Temperature Driven Evaporation

The Change in Water Vapor Heating compared to 1880 as a Result of Both Evaporative Responses

) Change in Average Global Temperature, $\Delta T_{\mathrm{Avg}}$

The change in average global temperature, $\Delta T_{\text {Avg }}$ is the area weighted average of changes in land, $\Delta T_{1}$, and ocean temperature, $\Delta T_{\text {SSII }}$. Therefore, with the seas covering $71.11 \%$ of the surface and land $28.89 \%$, the change in average global temperature is,

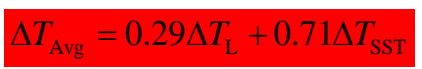

From Equation (10),

$$
\Delta T_{\mathrm{L}}=0.157 \Delta \mathrm{TH}^{\circ} \mathrm{C}
$$

From Equation (12), for the maximum increase, the surface temperature limit, $\Delta T_{\text {STLO }}$ for the seas,

$$
\Delta T_{\text {STLO }}=0.07 \Delta \mathrm{TH}^{\circ} \mathrm{C}
$$

\section{Since $\Delta T H=\Delta T_{\mathrm{I}} / 0.157$}

$\Delta T_{\text {STLO }}=0.07 \times \Delta T_{\mathrm{L}} / 0.157$

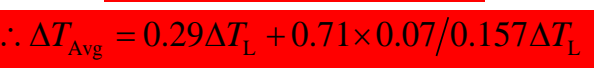

thus,

$$
\Delta T_{\text {Avg }}=\Delta T_{\mathrm{L}}(0.29+0.315)=0.605 \Delta T_{\mathrm{L}}
$$

Since

$$
\Delta T_{\mathrm{L}}=0.157 \Delta \mathrm{TH}
$$

\section{$\Delta T_{\text {Avg }}=0.605 \times 0.157 \Delta \mathrm{TH}=0.096 \Delta \mathrm{TH}$}

Thus, the Temperature Response Factor, $k_{T}$, to changes in total heating, $\Delta \mathrm{TH}$, is,

$$
k_{T}=0.096 \mathrm{~K} \cdot \mathrm{m}^{2} \cdot \mathrm{W}^{-1}
$$

Changes in Heating Driven by Changes in the Concentration of $\mathrm{CO}_{2}$

The theoretical change in heating driven by changes in the concentration, $C$, 
of $\mathrm{CO}_{2}, \Delta \mathrm{TH}_{\mathrm{CO} 2}$, is

$$
\Delta \mathrm{TH}_{\mathrm{CO} 2}=5.35 \ln \left(C / C_{o}\right) \mathrm{W} \cdot \mathrm{m}^{-2}
$$

Change in Total Heating

If in the change in total heating, $\Delta \mathrm{TH}_{\mathrm{Tot}}, \mathrm{CO}_{2}$ were a factor, then the total change in heating would be,

$$
\Delta \mathrm{TH}_{\mathrm{Tot}}=5.35 \ln \left(C / C_{o}\right)+\Delta \mathrm{WV}_{\mathrm{Tot}}
$$

\section{2) Change in Average Global Temperature}

The total increase in average global temperature, $\Delta T_{\mathrm{Avg}}$, in response to the total change in heating, $\Delta \mathrm{TH}_{\mathrm{Tot}}$ is, therefore,

$$
\Delta T_{\mathrm{Avg}}=k_{T} \Delta \mathrm{TH}_{\mathrm{Tot}}
$$

